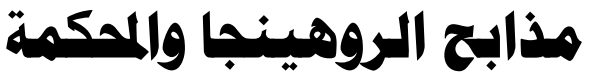

\section{الجنائية الدولية}
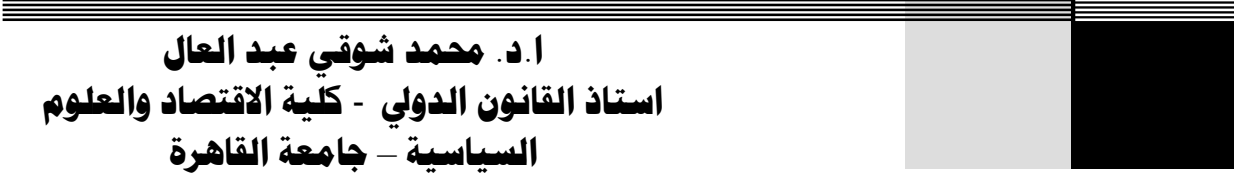

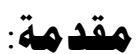

شهر عام 1 1 ـ r مآسي إنسانية رهيبة بحق مسلمي أقلية الروهينجا فـي

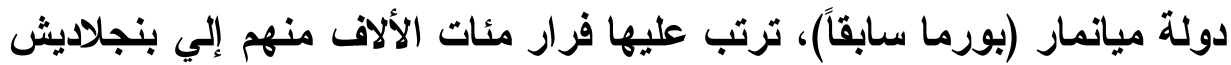

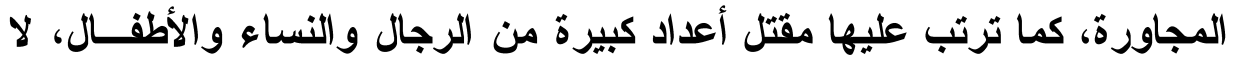
لشئ سوي أنهم ينتمون إلي هذه الأقلية المضطهةة، حيث قامت قوات اتلهن الجيـش والثرطة فى ميانمار باستخدام القوة المفرطة بحقهم. وقد جاءت هذه الهجمات

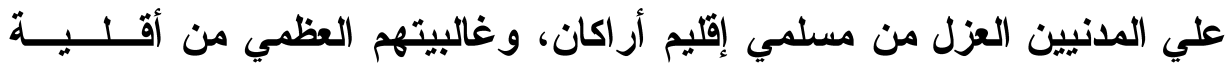

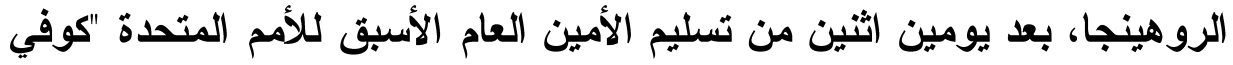
عنان" تقريراً نهائياً لحكومة ميانمار بشأن تقصي الحقائق في أعمال عنف سابقة

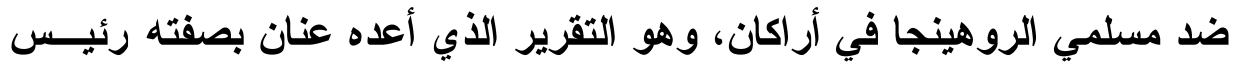

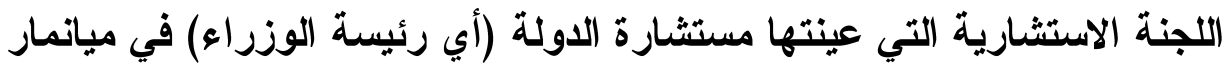
ذاتها، وانتهي فيه إلي إدانة سلوك القوات المسلحة لميانمار عما فعلته بحق هذه الهن الأقلية المسلمة، ومن ثم فقد جاء الهجوم من الجيش علي المدنيين المسالميـن إنهات

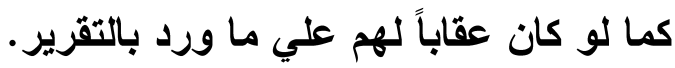

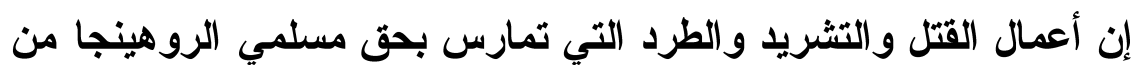
جانب قوات الجيش والثرطة فى ميانمار ليست أمراً جديداً، فمثل هذه الأعمــال وما يقترن بها من انتهاكات صارخة لحقوق الإسان هي سياسة ممنهجة تتبعها 


\section{娄}

السلطات هناك منذ عشر ات السنين. ويكفي أن نثير في هذا الصدد، وعلي سبيل

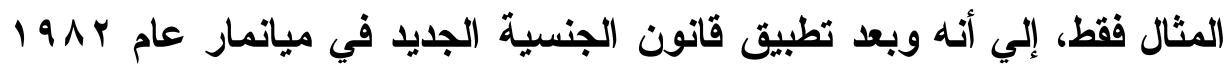

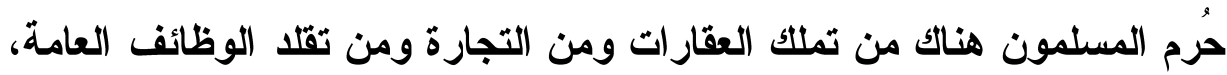

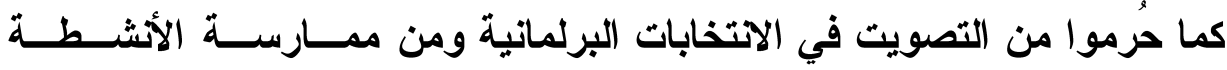

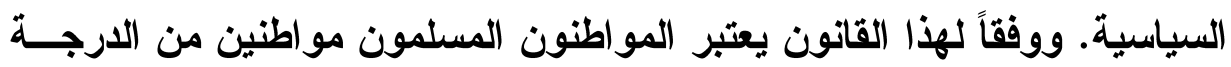

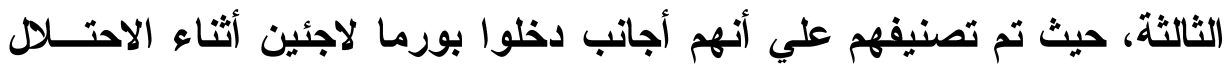

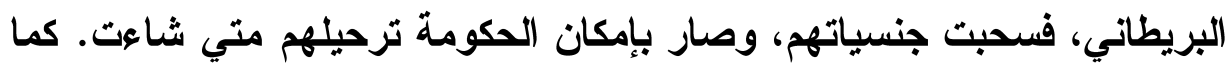

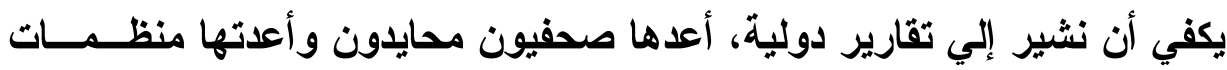

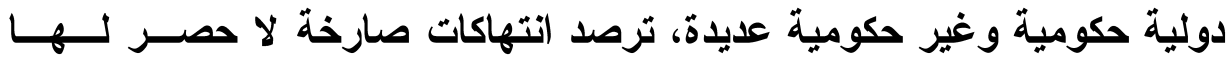

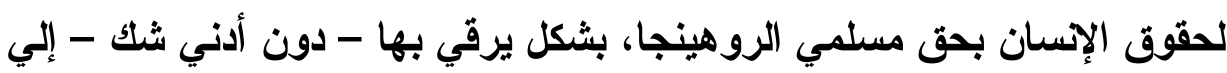

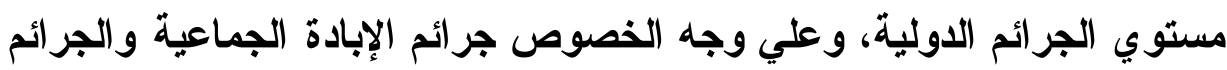

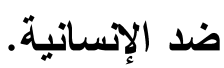

ويقصد بالجريمة الدولية كل فعل أو سلوك إيجابي أو سلبي (بمعني القيام

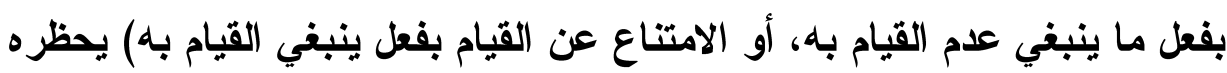

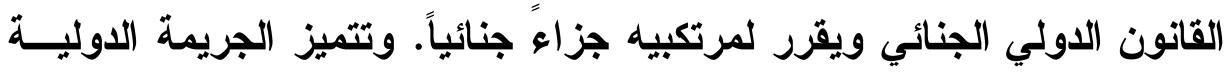

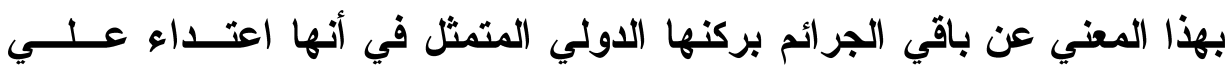

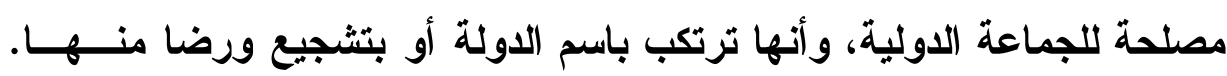

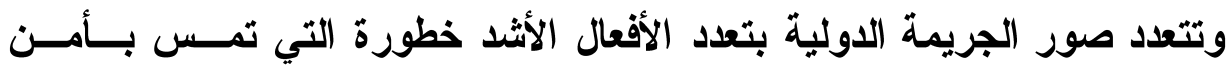

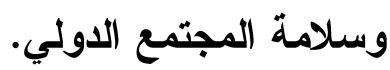
ويعد ميثاق روما الأساسي لعام 1991 المنثئ للمحكمة الجنائية الدولية

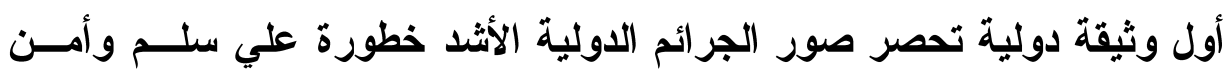
المجتمع الدولي، و التي اتفق هذا المجتمع علي طبيعتها الدولية. 


\section{(6)}

ومن المعلوم أن الإبادة الجماعية والجرائم ضد الإسانية هما جريمتان من

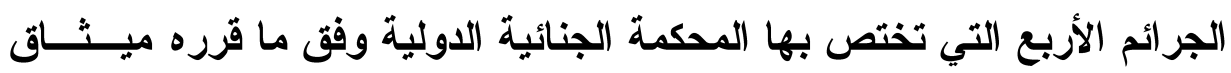

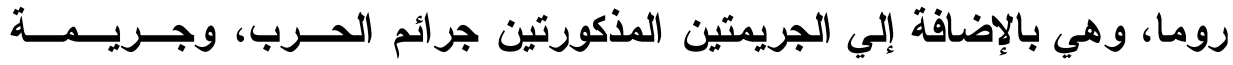

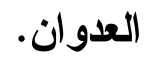

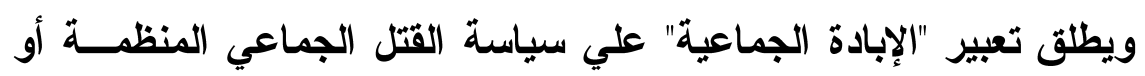

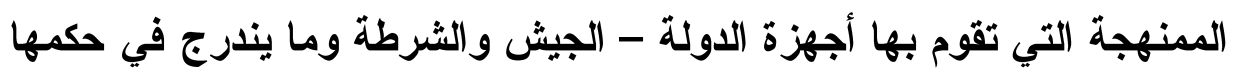
- ضد جماعة أو جماعات معينة من شعب هذه الداولة، لأسباب عرقية أو دينية

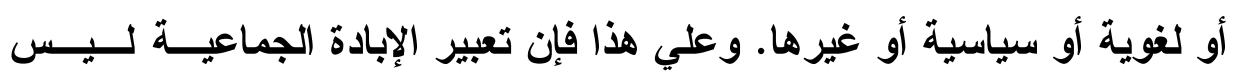

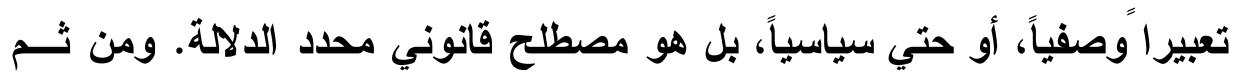

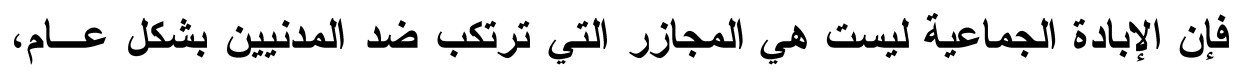

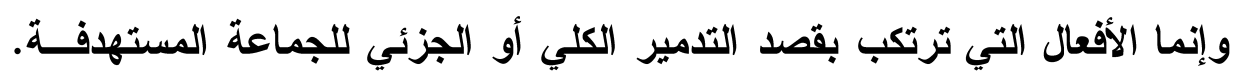

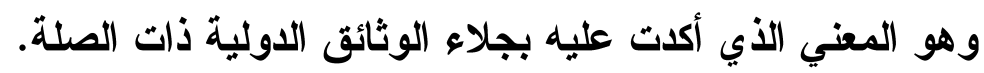

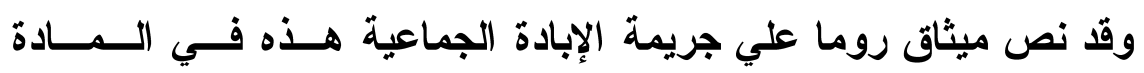

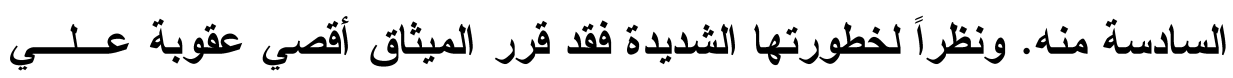

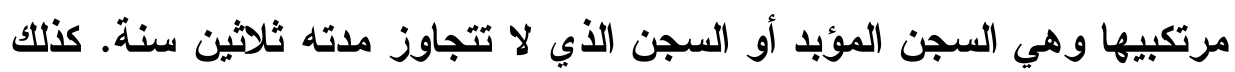

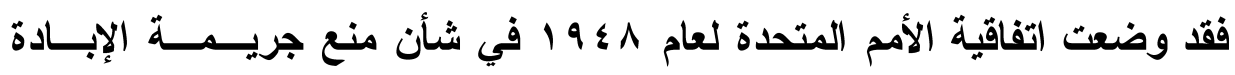

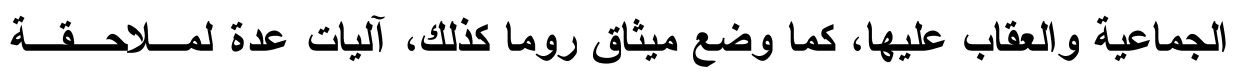

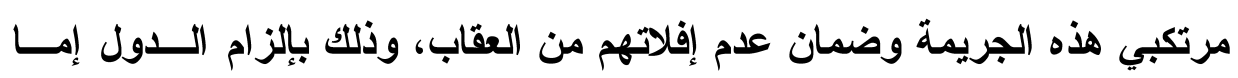
بمحاكتهم أو تسليمهر.

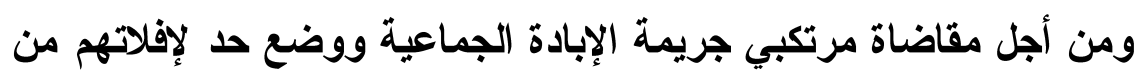

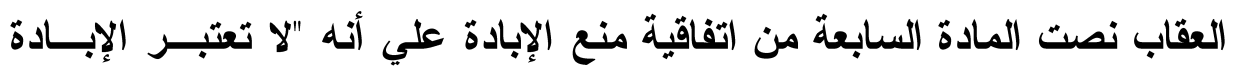

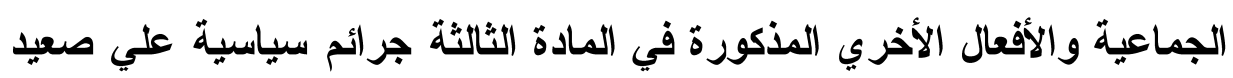




\section{娄}

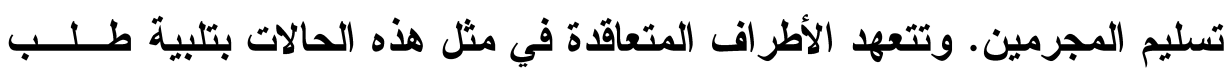

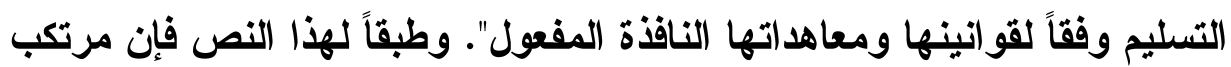

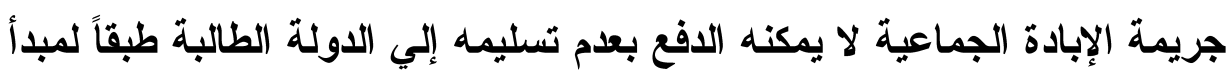
عدم جواز التسليم في الجرائم السياسية.

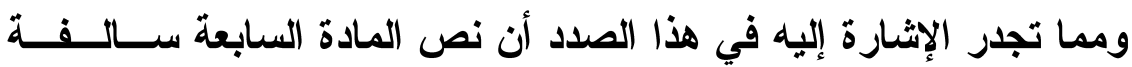
البيان غير كاف في ذاته كأساس قانوني للتسليم في جريمة الإبادة الجماعيـة، الإنة

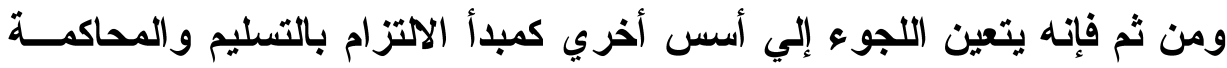

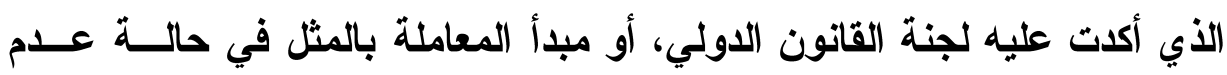

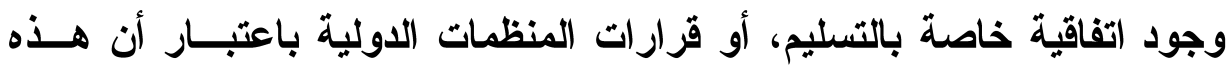

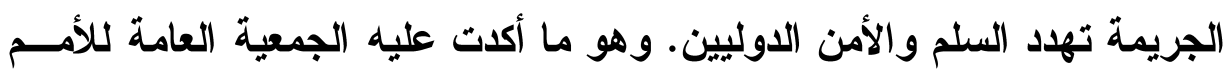

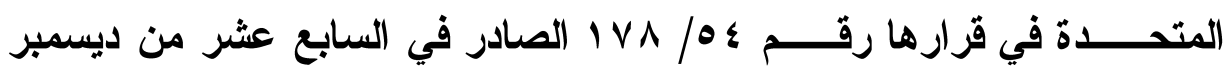

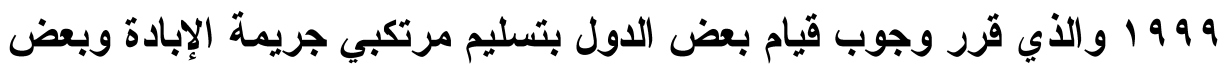

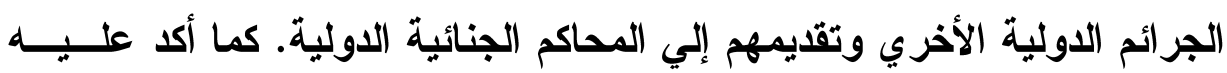

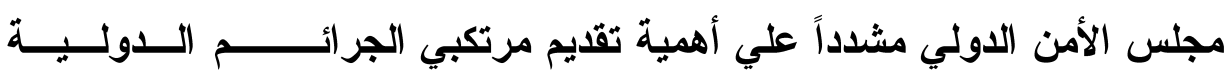

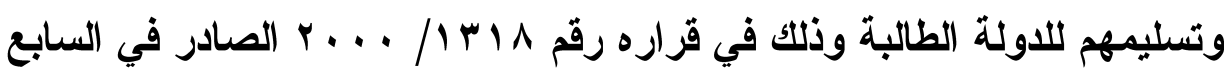

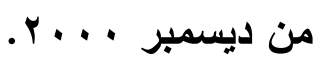
وترتيباً علي ما سبق فإن مرتكب جريمة الإبادة الجماعية لا يمكنه الإفلات

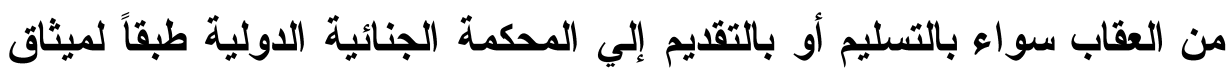

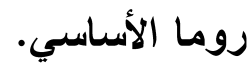

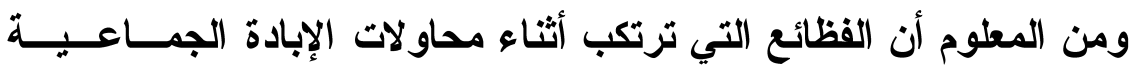

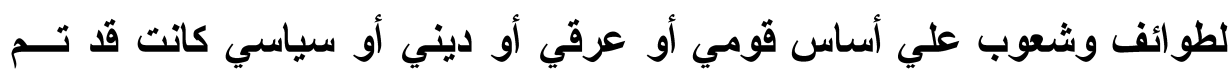

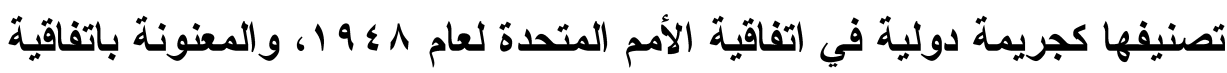




\section{(6)}

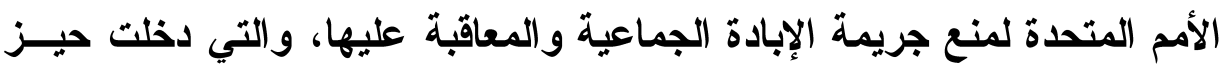

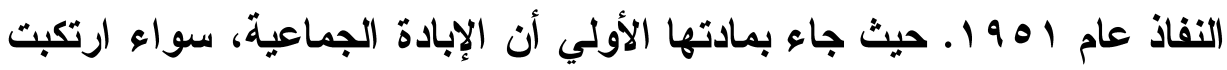

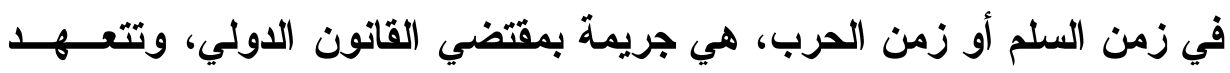

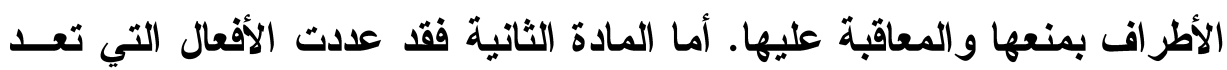

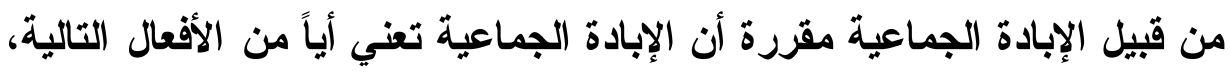

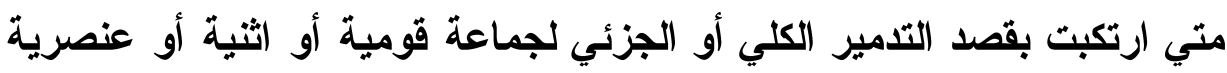
أو دينية بصفتها هذه. وقد عددت المادة المذكورة هذه الأفعال في الآتي:

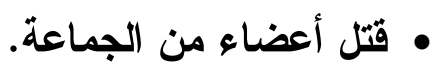
• • إلحاق أذى جسدي أو روحي خطير بأعضاء من الجماعة.

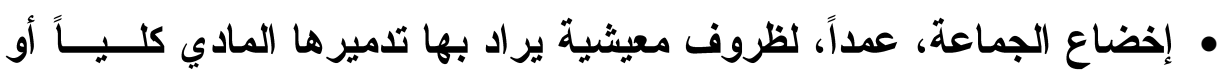
جزئياً. • فرض تدابير تستهذف الحؤول دون إنجاب الأطفال داخل الجماعة. • • لمقل أطفال من الجماعة، عنوة، إلي جماعة أخروي.

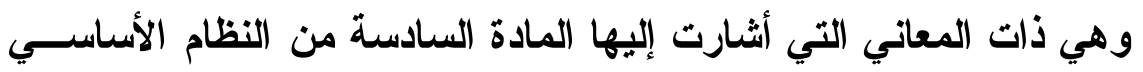

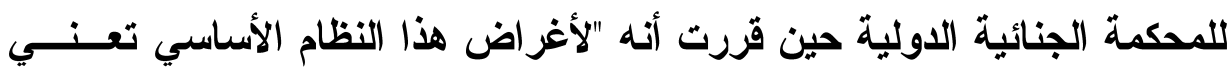

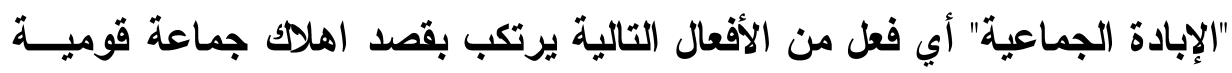

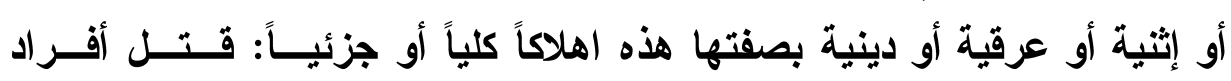

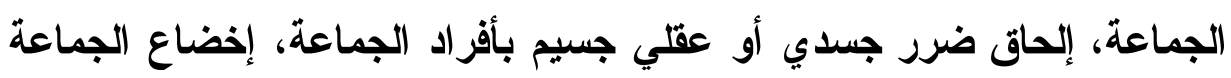

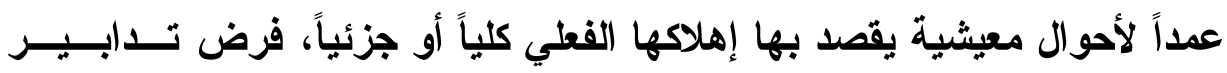

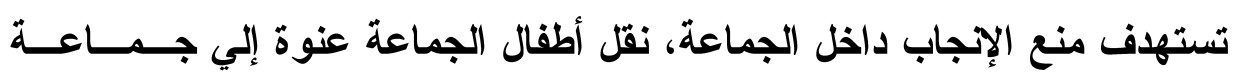

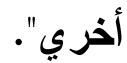

وهكذا فإن الإبادة الجماعية وفقاً للنظام الأساسي للمحكمة الجنائية الدولية

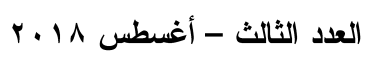
$\wedge$ ฯ 


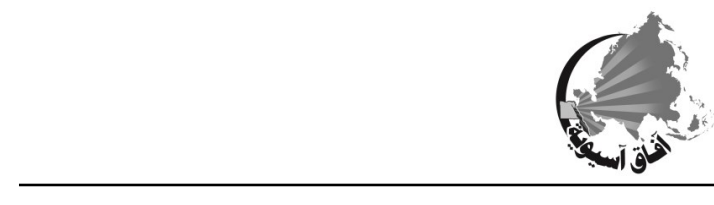

تثثمل الأفعال التالية:

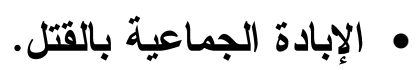

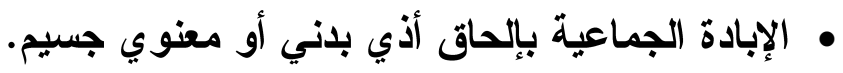
• الإبادة الجماعية بفرض أحوال معيشية يقصد بها التسبب عمداً فــي إهـلاك إلكان

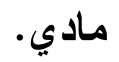
• • الإبادة الجماعية بفرض تدابير تستهذف منع الإجاب. • إلإبادة الجماعية بنقل الأطفال قسراً.

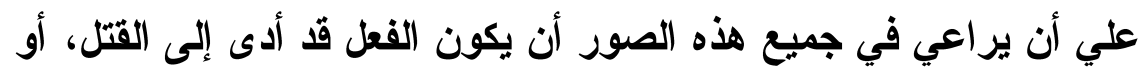

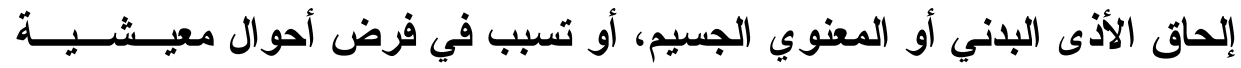

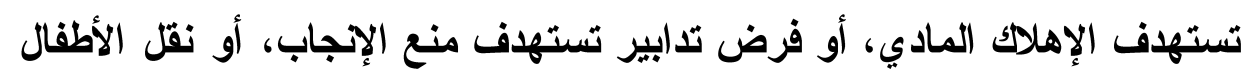

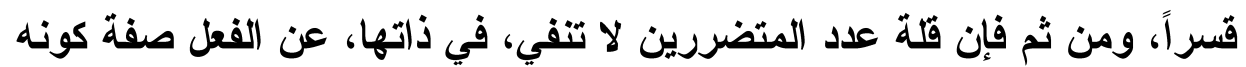

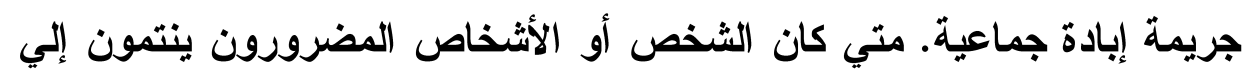

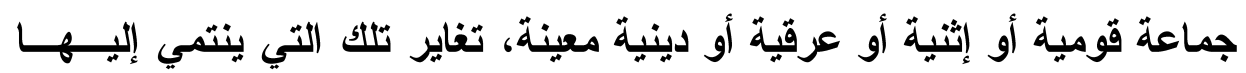

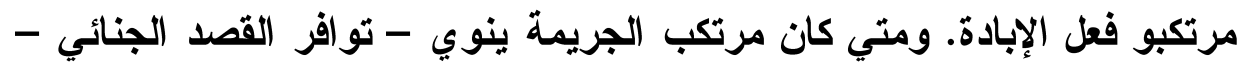

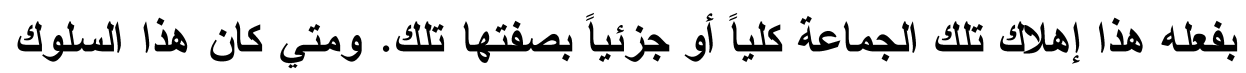

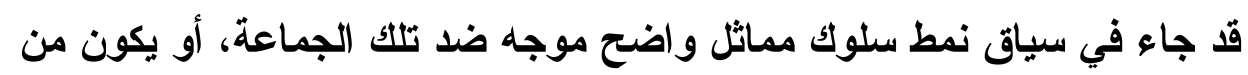
شأن السلوك أن يحدث بحد ذاته ذلك الإهلاك فئك.

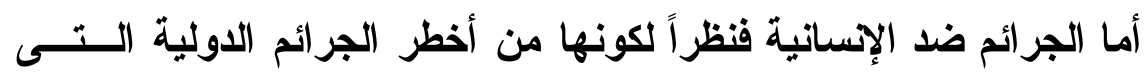

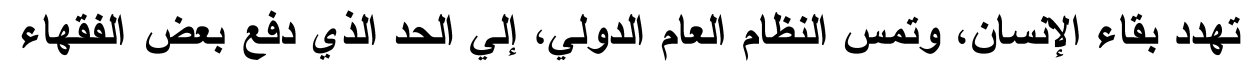

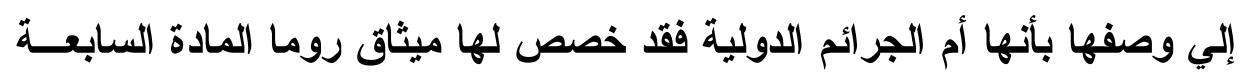

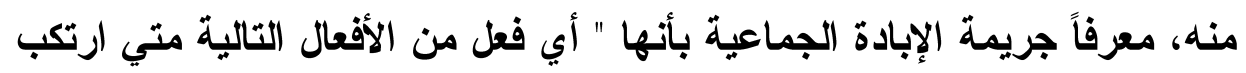

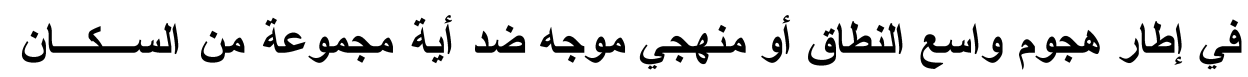




\section{6.}

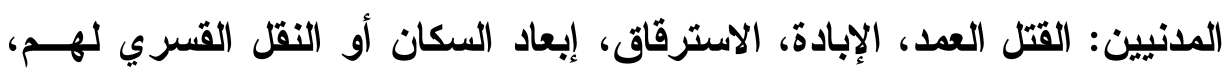

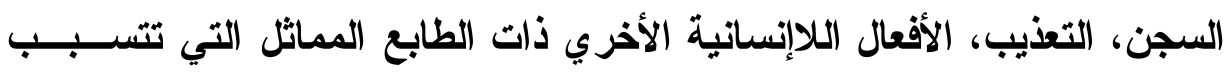

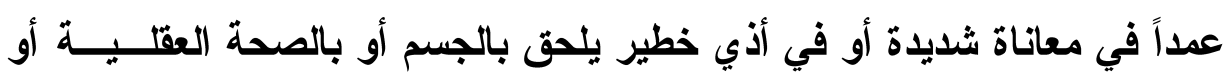
البانية ".

وفي هذا الاطار تعد الجرائم ضد الإسانية جرائم دولية بطبيعتها بالنظـر

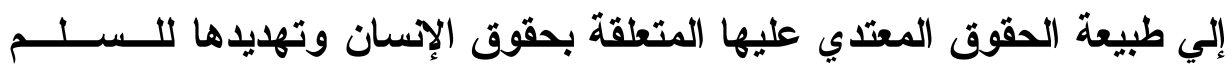

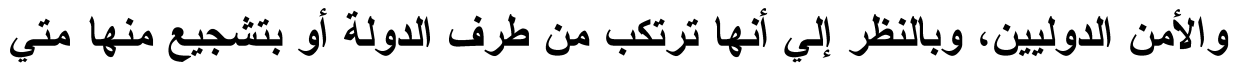

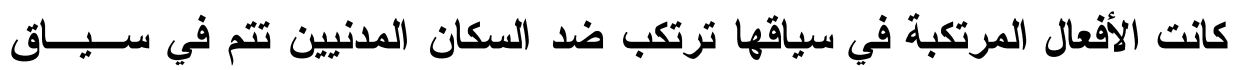
سياسة منهجية تنظيمية واسعة النطاق. وجدير بالإشارة في هذا الصدد أنه عند وقوع هذا النوع النو من الجرائم فــي

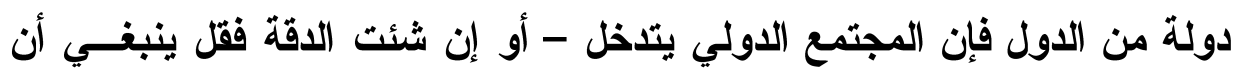

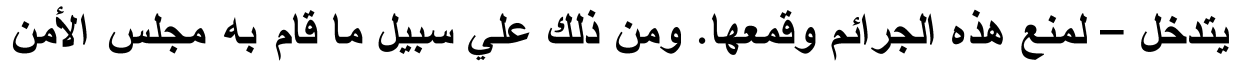

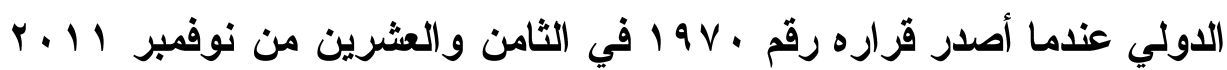

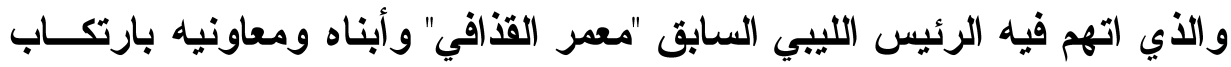

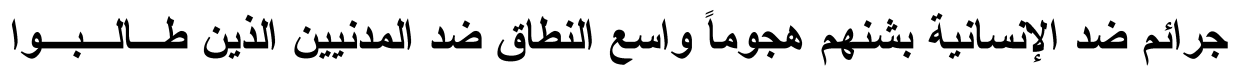

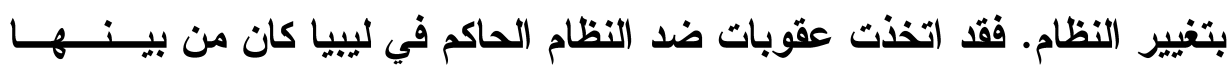

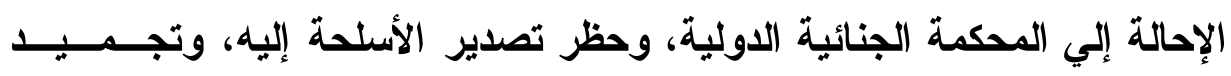

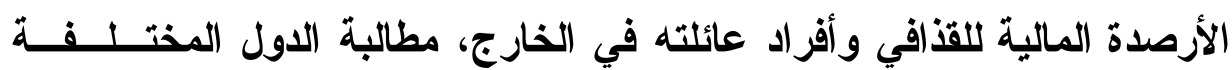
بالتعاون لقمع هذه الجرائم.

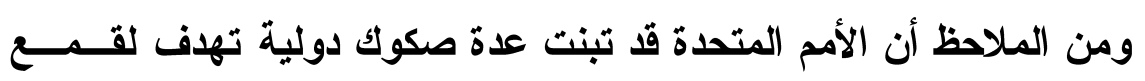

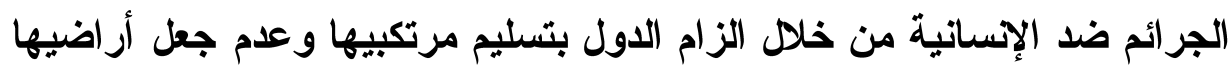

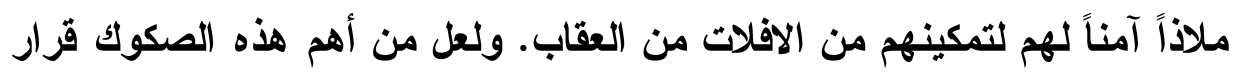




\section{6.}

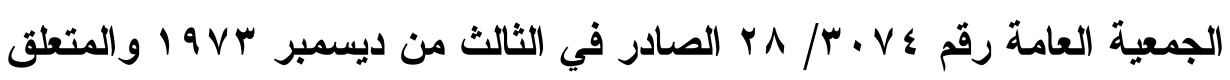

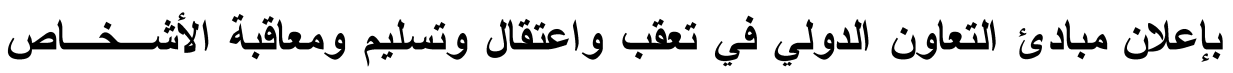

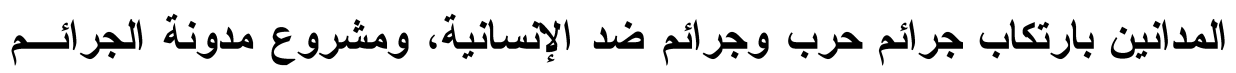

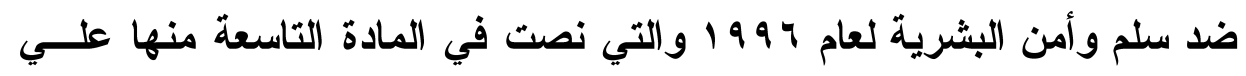

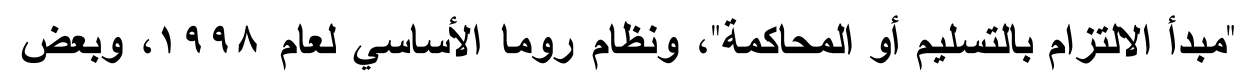

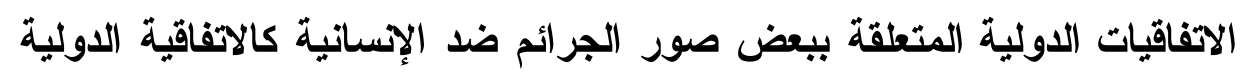

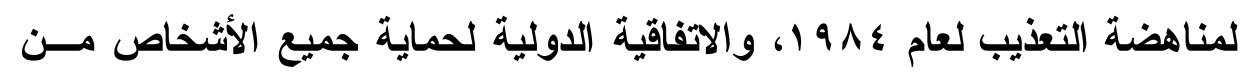

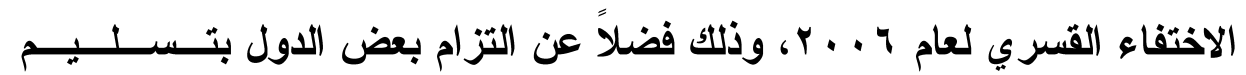

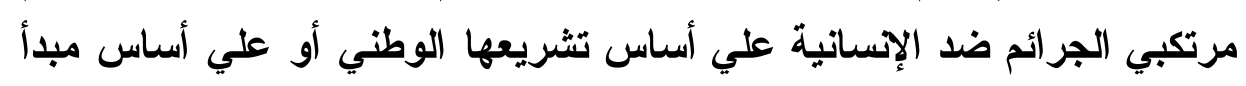

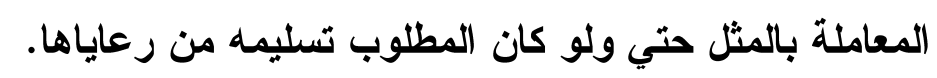

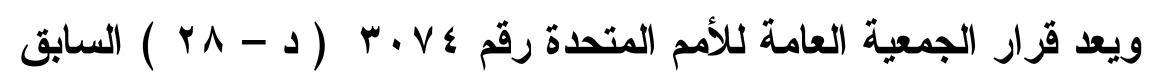

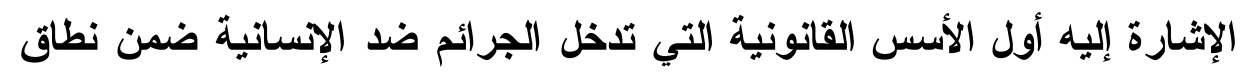

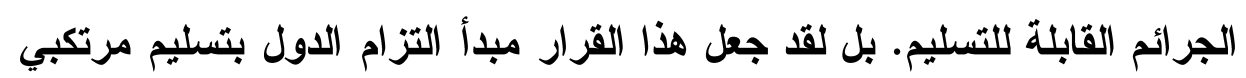

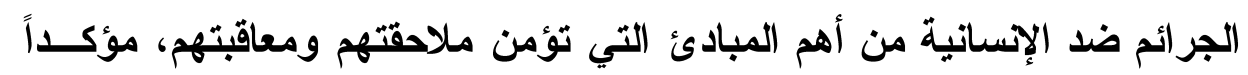

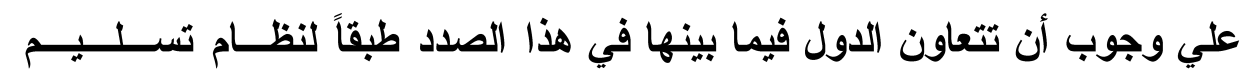

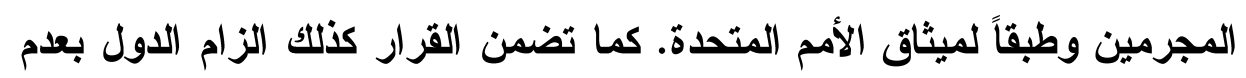

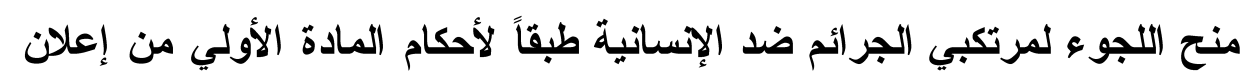

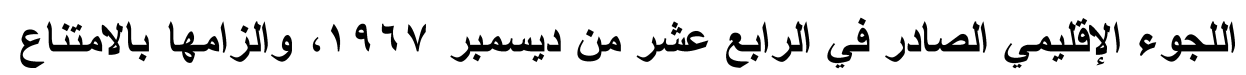

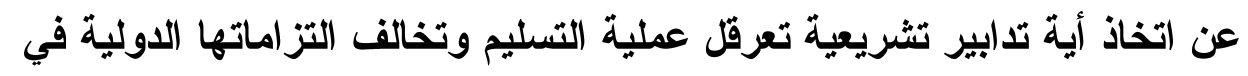

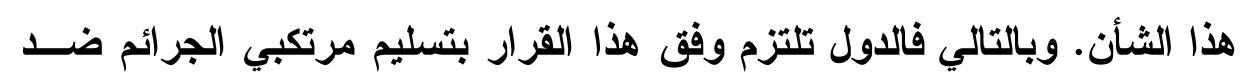

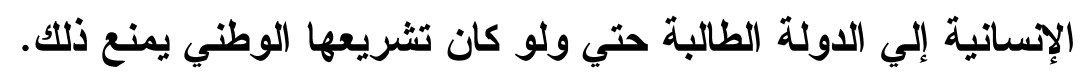

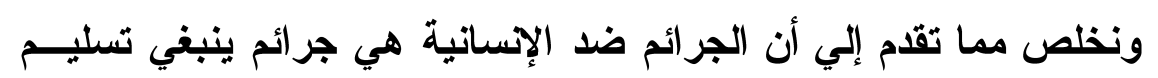




\section{曹}

مرتكبيها من أجل محاكتهم وتوقيع العقاب عليهم متي ثبتت التهمة، كما يتعين

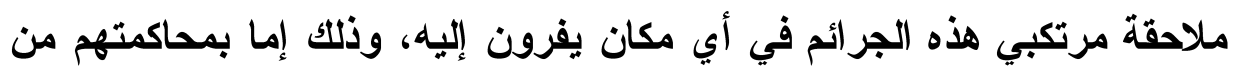

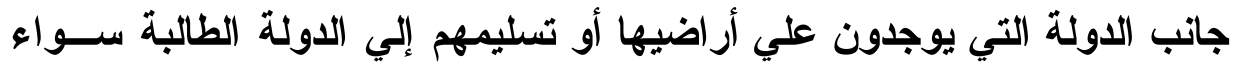

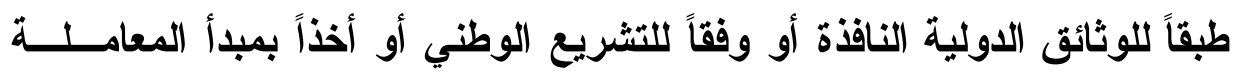

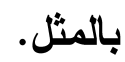

و وانطلاقاً من هذه الحقائق يأتي السؤال الذي نحاول الإجابة عليه في هــــا

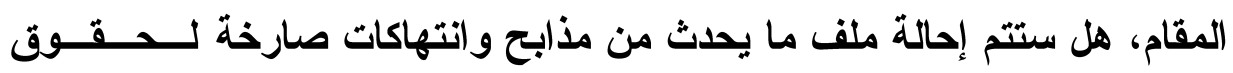

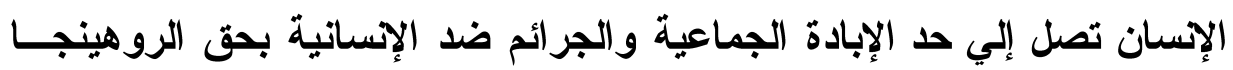
إلي المحكمة الجنائية الدولية؟ الإنج

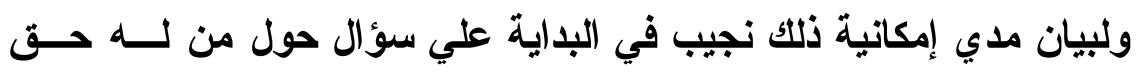

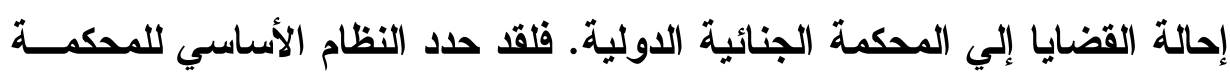

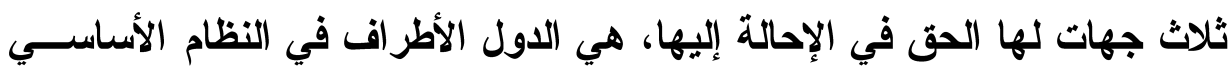

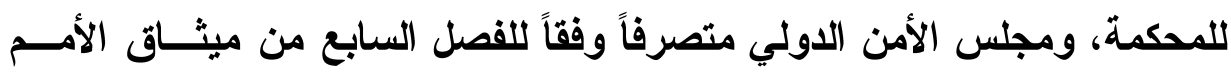

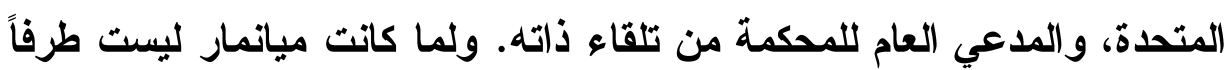

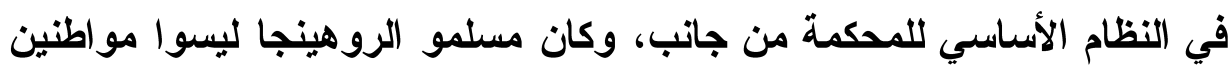

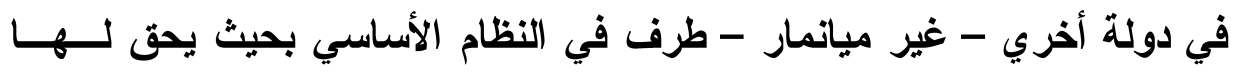

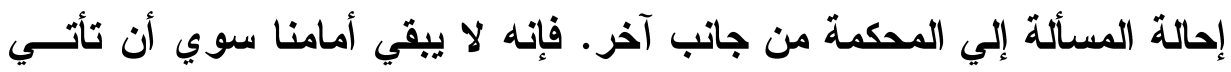

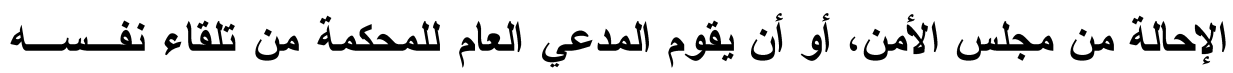
بذلك.

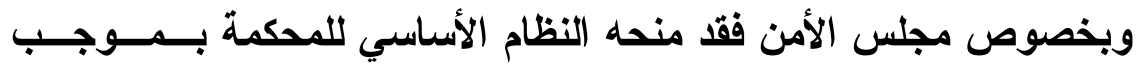

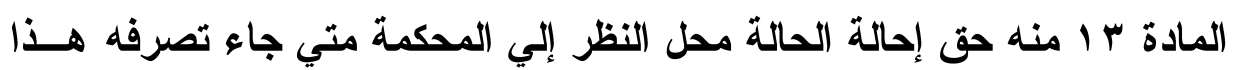
مستتداً إلي الفصل السابع من ميثاق الأمم المتحدة. وقد استخدم المجلس سلطته

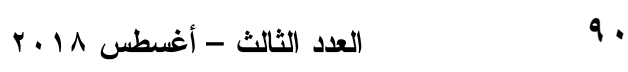




\section{6}

هذه بالفعل مرتين، مرة في قراره رقم بوه ا لعام ه . . ب بإحالة الوضع فـي

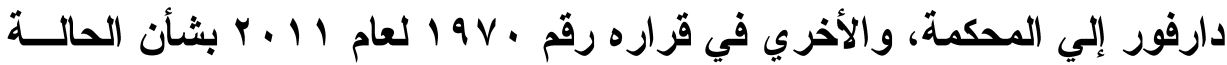
الليبية. علي أن مجلس الأمن قد امتنع عن ممارسة هذه السلطة فـي حــالات أخري عديدة كان الوضع فيها يستدعي الإحالة إلي المحكمة، كحالات الاعتــــاء

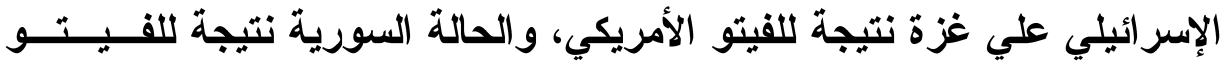
الروسي والصيني. وعلي الرغم من سيطرة الاعتبارات السياسية علي قــرارث

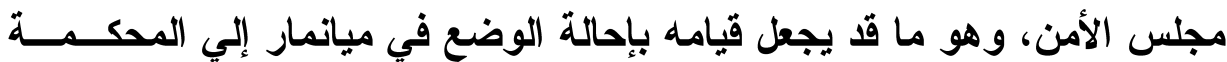
أمراً تحيطه شكوك كثيرة، فإن فداحة الجرائم المرتكبة بحق مسلمي الروهينجا، والتي أشارت إلي جاتب منها الأمم المتحدة ذاتها في تقاريرها الأخيرة، فضــلاً عن تهديد الوضع للسلم والأمن الاوليين في المنطقة، قد يدفع مجلس الأمن إلي تبني قرار بالإحالة إلي المحكمة الجنائية الدولية، سيما إذا تبنت الاول الإسلامية في الأمم المتحدة، والتي يريو عددها علي الخمسين دولة، تدعمها - بداهة دول كثيرة غير مسلمة، موقفاً موحداً في هذا الصدد، علي أن الأمر سيبقي علي الاوام في هذا الصدد محكوماً بمدي إمكانية تحقيق التوافق بين الدول الخمسس الكبري دائمة العضوية في مجلس الأمن، للحيلولة دون استخدام أي منها لحــق النقض "الفيتو" لمنع اصدار قرار من المجلس بشأن إحالة الوضع في ميانـــــار إلي المحكمة.

أما بخصوص الطريقة الأخيرة من طرق الإحالة إلي المحكمة وهي قيــام المدعي العام للمحكمة من تلقاء نفسه بفتح باب التحقيق في مسألة من المسائل علي أساس معلومات متعلقة بجرائم تلخل في اختصاص المحكمة تصل إلي علمه من مصادر موثقة، أو يستقبها هو من أي مصدر كان، كالحكومات والمنظمــات

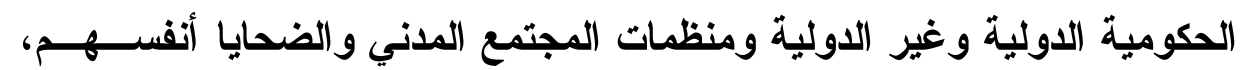




\section{(4)}

وهو الاختصاص الأي منحته إياه المادة 10 من النظام الأساسي للمحكمة، فربما

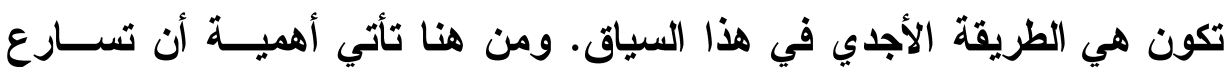

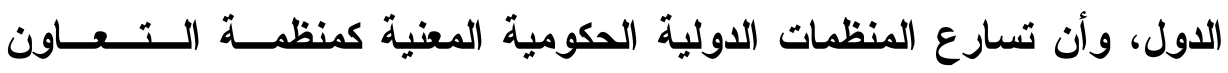

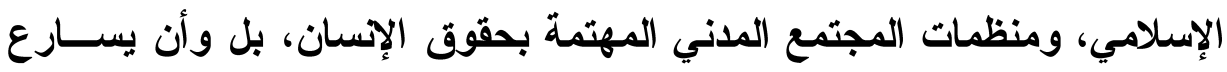

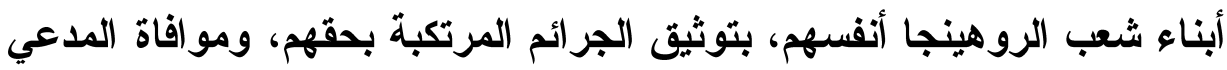

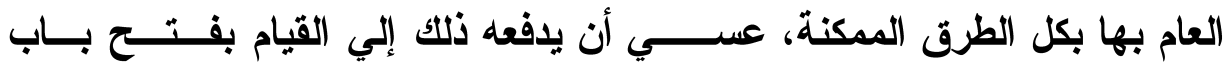

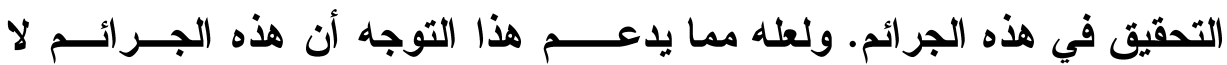

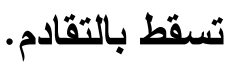

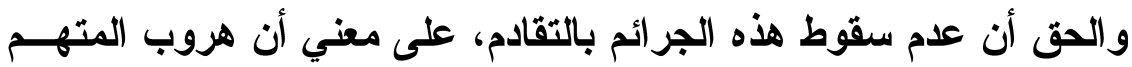

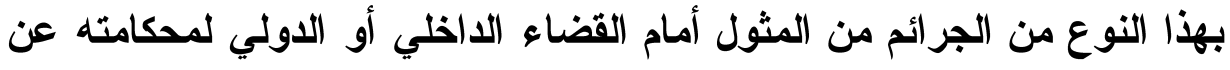

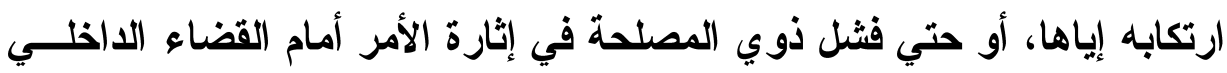

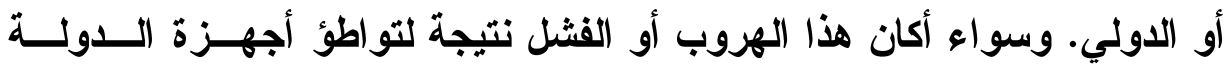

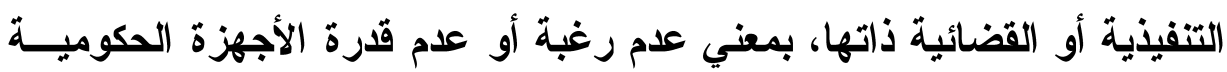

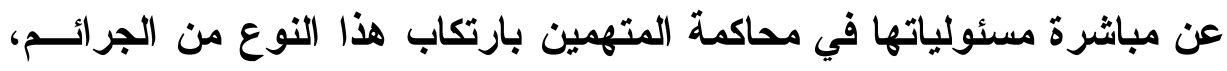

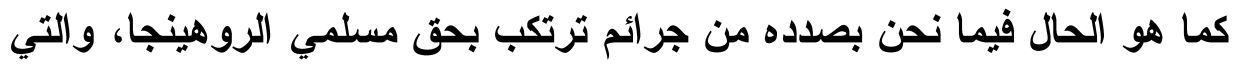

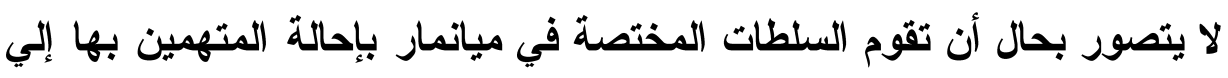

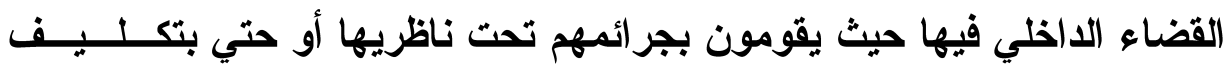

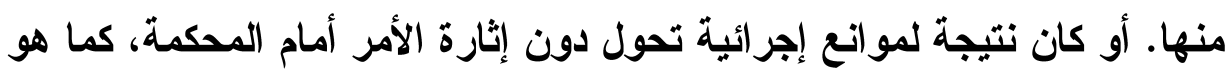

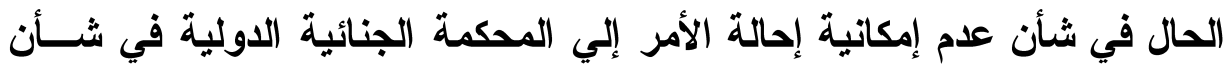

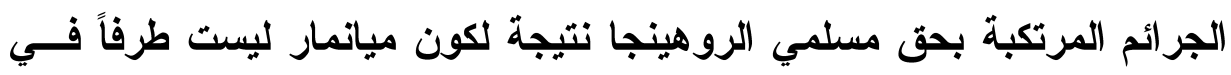

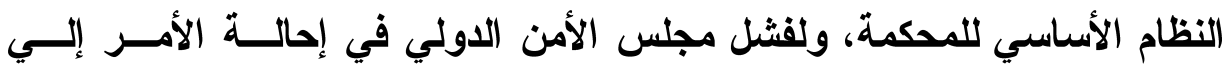

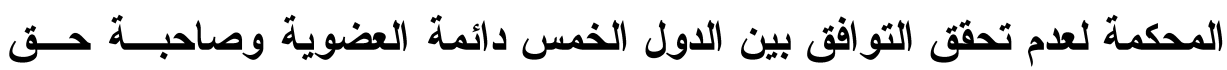




\section{覀}

التقض فيه، وعدم اضطلاع المدعي العام بدوره في فتح التحقيق في القضية من تلقاع نفسه لعدم كفاية ما لايه من معلومات مثلاً للقيام بهذا الاور. إن هروب المتهم، أو الفشل في إثارة الأمر أمام القضاء، لا يــؤدي وإن طال المدي، إلي سقوط الاتهام بهذا النوع من الجرائم. فيقيقي الاتهام قــائــــــاً، وتبقي إمكانية إثارة الأمر أمام القضاء الداخلي أو الاولي واردة، ويبقي المتهـــ معرضاً للإدانة، ولو مرث عشرات السنين بين فعل الجرم والمحاكمة عليه. وهو

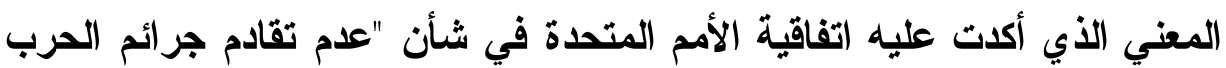
والجرائم المرتكبة ضد الإنسانية" التي تم التوقيع عليها في السادس والعشريسن

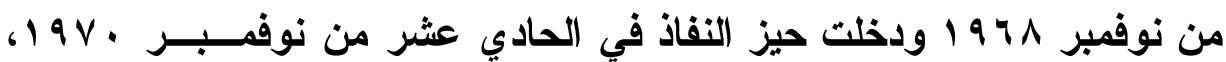

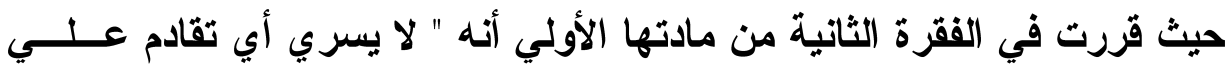
الجرائم التالية بصرف النظر عن وقت ارتكابها:

الجرائم المرتكبة ضد الإسسانية، سواء في زمن الحرب أو زمن الســـــم،

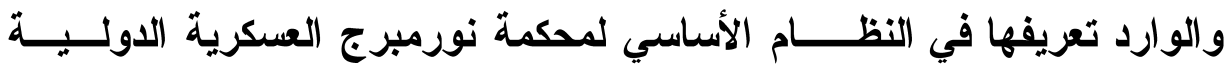

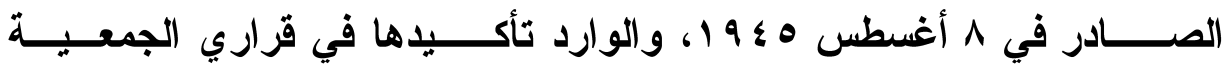
العامــة للأمم المتحدة r (د - 1) المؤرخ في ب ا فبرايـر

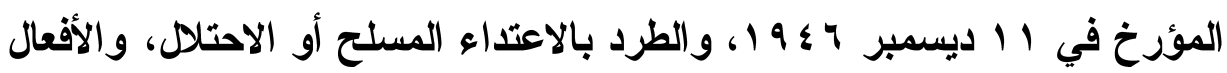
المنافية للإنسانية والناجمة عن سياسة الفصل العنصري، وجريـــــة الإبــادة الجماعية الوراد تعريفها في اتفاقية عام ^ ^ 9 1 بشأن منع جريـــــة الإبــادة الجماعية والمعاقبة عليها، حتي لو كانت الأفعال المذكورة لا تشـــــل إخــلالاً بالقانون الاخلي للبلد الأي ارتكبت فيه". ولقد أكد النظام الأساسي للمحكمة الجنائية الدولية مبدأ عدم التقادم هـــا بشكل أكثر وضوحاً وحسماً في المادة و ج منه والتي جري نصها علي أنـــه "لا 


\section{6.}

تسقط الجرائم التي تدخل في اختصاص المحكمة بالثقادم أباً كانت أحكامه". ومن

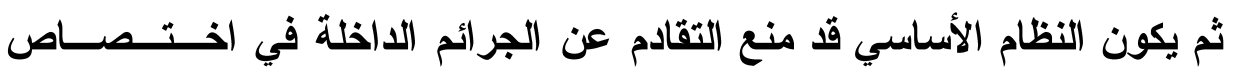

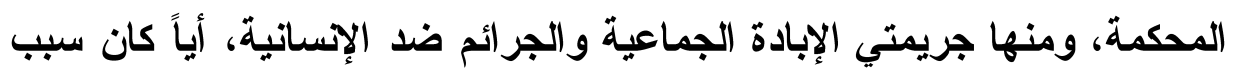

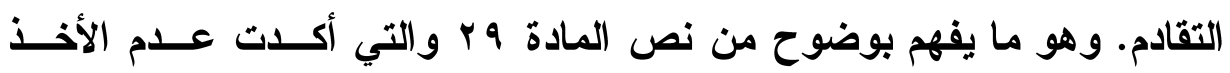

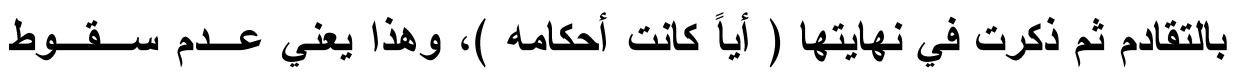

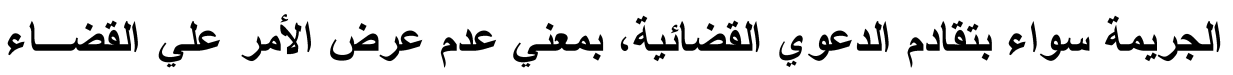

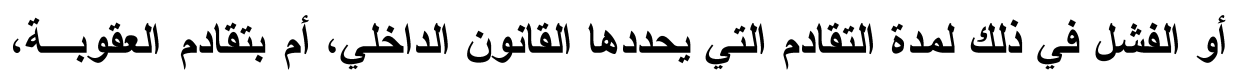

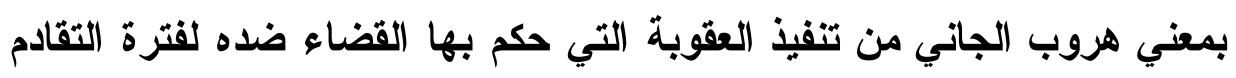

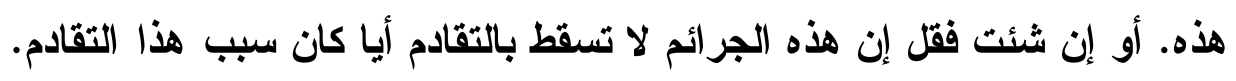

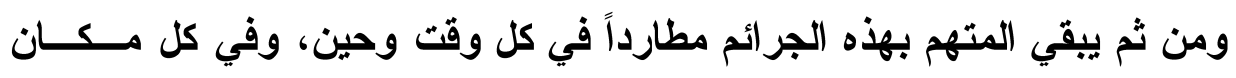

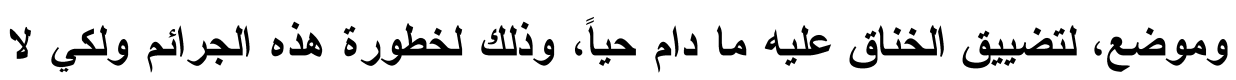

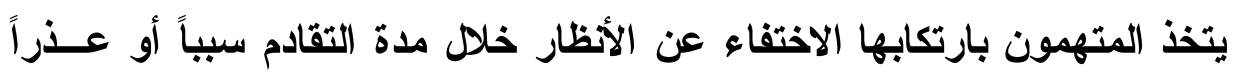
للتهرب من المساعلة الجنائية وتفادي العقاب.

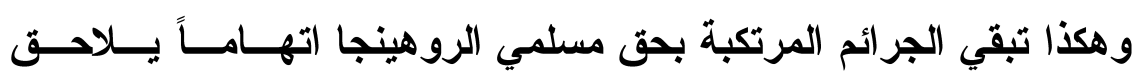

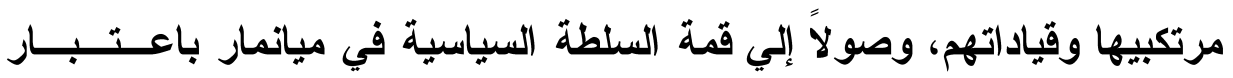

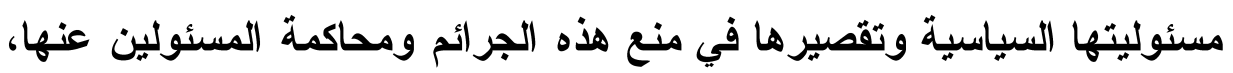

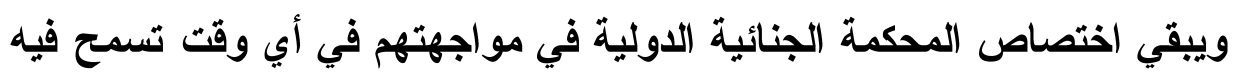

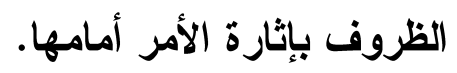

